\section{THE TEACHING OF THERAPEUTICS.}

New York, Oct. 1, 1913.

Mr. Editor: Your admirable editorial in the issue of September 25, apropos of "The Teaching of Therapeutics," does not emphasize, as I believe it should, the great value of life-long experience of the practitioner, aside scientific explanation. There are formulae which have undoubted and great value, and yet we do not know precisely, upon what their efficacy in the cure of disease depends. Such a one is Warburg's Tincture-I do not believe one can cure certain forms and cases of chronic malaria, without it. This I have tested, and proved to my own satisfaction, not infrequently.

There are simple remedies that were much used in my early days, and are now almost lost sight of practically, that are really more useful, and far less objectionable, than many of the newer drugs, no matter how much they may be supported by the later science. To teach therapeutics to students in the best way, it seems to me, the older practitioner should make the rounds of the hospital ward frequently, with the attending staff, and when the younger men are through with their examinations, and statements, he should be called upon respectfully to express his views, product of much that he has seen, tried and learned.

I should be unwilling to abandon that knowledge of drugs and their uses, which I have learned almost solely outside and independently of the hospital ward. We should constantly bear in mind what we seem constantly to ignore, or forget, that practice among our private patients, and practice in the hospital, differs in many ways. To begin with, the habits and antecedents of those who are ill, differ essentially, as a rule.

Again, I defy any physician, no matter how learned he may be, to obtain successful results with patients, unless he strives, so far as possible, to observe and absorb, as it were, their personal idiosyncracies to drugs and treatment of any sort.

A mere nothing in the way of a drug, as treatment, will frequently make the very great difference between success, or failure, as to cure, temporary, or permanent.

Indeed, relief from painful, or annoying symptoms, is only thus obtained when cure is impossible.

Beverley Robinson, M.D.

\section{NOTICE.}

Wednesday Noon Cuinics in Mental Disease for General Practitioners, Psychopathic Hospital, Boston.- Until further notice, clinics in mental disease for general practitioners will be given by members of the Psychopathic Hospital staff on successive Wednesdays (omitting holidays) from 12 noon to 1 . p.m. The discussions and demonstrations will be held either in the library or in the assembly room (occasionally in the wards) of the hospital.

In offering these clinics, the trustees of the Boston State Hospital (of which the Psychopathic Hospital is a department) are endeavoring to provide a profitable kind of post-graduate work in mental diseases for general practitioners (particularly of the Metropolitan District) and thus to make the Psychopathic Hospital " $a$ center of education and training of physicians" (see Report of State Board of Insanity, Pub. Doc. No. 63, 1910, p. 30).

The clinical material of the hospital is ample for the demonstration of all classes of mental patients, particularly in the earlier phases of their diseases or attacks. Attendance upon a fair proportion of the Wednesday clinies during the season should insure to the practitioner a good review of modern psychiatric diagnosis.

Practitioners wishing notification of the topics and cases to be especially discussed at particular meetings should advise the director to that effect.

There is no fee for these clinics, to which all Massachusetts practitioners are cordially welcomed.

(Practitioners are also invited to the staff meetings held on other week days (except holidays) at the same hour; these are devoted to more advanced, obscure, or special topics, having to do with the investigative or medico-social sides of the hospital work.)

The hospital is at 74 Fenwood Road, Boston, and can be reached either by Chestnut Hill cars, alighting at corner of Fenwood Road and Brookline Avenue, or by South Huntington Avenue and Brookline Village cars, alighting at corner of Fenwood Road and Huntington Avenue.

E. E. Southard, M.D., Director.

74 Fenwrood Road, Boston, Mass.

\section{APPOINTMENTS.}

Harvari Medical School.-At a recent meeting of the Roard of Overseers of Harvard College, the appointments were approved of $\mathrm{Dr}$. John Hildreth McCollom, as emeritus professor of contagious diseases, of $\mathrm{Dr}$. Reid Hunt as professor of pharmacology, and of Dr. Worth Hale as assistant professor of pharmacology in the Harvard Medical School.

UNIVERSITY OF KANSAS.-D $r$. $G$. $E$. Coghill has been appointed associate professor of anatomy at the Lniversity of Kansas.

Western UNIVERSITy OF LONDON.-Dr. Paul s. McKibben has been appointed professor of anatomy at the Western University of London, Ontario.

Boston City Hospital.-Dr. Halsey Beach Loder has recently been appointed third assistant visiting surgeon to the Boston City Hospital.

\section{RECENT DEATHS.}

Dr. OrRen BurnhaM Sanders, of Boston, who died on Sept. 25 as the result of an automobile accident at Quincy, Mass., was born in Epson, $\mathbf{N}$. H., on Nov. 18, 1855. After graduating from the Boston Latin School in 1874, he studied for two years at Amherst College, and in 1879 received the degree of M.D. from Boston University. He was an out-patient physician to the Massachusetts Homeopalhic Hospital; lecturer on genito-urinary diseases at Boston University Medical School; a member of the American Institute of Homeopathy, of the Massachusetts and Boston Homeopathic Medical Societies, and of the Massachusetts Surgical and Gynecological Societies; and since 1909 a Fellow of The Massachusetts Medical Society.

Dr. Charles Lester Leonard, of Philadelphia, who died at Atlantic City, N. J., on Sept. 22, of x-ray epithelioma, was born in 1858 . He received the degree of A.B. from Harvard College in 1886, and that of M.D. in 1889 from the University of Pennsylvania.

Dr. AlFred T. Birdsall, who died of pneumonia recently at Brooklyn, $N$. Y., was born in that city in 1870. He graduated from the University of Minnesota in 1896, and in 1899 began the practise of his profession at Brooklyn. He was instructor in surgery at the New York Post-graduate Medical School and a member of the Kings County Medical Society. He is survived by his widow and by one son.

Dr. William H. K. Davis, who died of nephritis on Sept. 24, at East Orange, N. J., was born in 1863. He received his medical degree in 1886 from the New York College of Physicians and Surgeons. He was a member of the American Medical Association and of the New Jersey State Medical Society. He was not married. 